\title{
Absorption cross-section measurements of methane, ethane, ethylene and methanol at high temperatures
}

\author{
Majed Alrefae, Et-touhami Es-sebbar, Aamir Farooq* \\ Clean Combustion Research Center, Division of Physical Sciences and Engineering, King \\ Abdullah University of Science and Technology (KAUST), Thuwal 23955-6900, Saudi Arabia \\ *Corresponding author, Email: aamir.farooq@kaust.edu.sa, Telephone: +966128082704
}

\begin{abstract}
Mid-IR absorption cross-sections are measured for methane, ethane, ethylene and methanol over $2800-3400 \mathrm{~cm}^{-1}(2.9-3.6 \mu \mathrm{m})$ spectral region. Measurements are carried out using a FourierTransform-Infrared (FTIR) spectrometer with temperatures ranging $296-1100 \mathrm{~K}$ and pressures near atmospheric. As temperature increases, the peak cross-sections decrease but the wings of the bands increase as higher rotational lines appear. Integrated band intensity is also calculated over the measured spectral region and is found to be a very weak function of temperature. The absorption cross-sections of the relatively small fuels studied here show dependence on the bath gas. This effect is investigated by studying the variation of absorption cross-sections at $3.392 \mu \mathrm{m}$ using a $\mathrm{HeNe}$ laser in mixtures of fuel and nitrogen, argon, or helium. Mixtures of fuel with $\mathrm{He}$ have the highest value of absorption cross-sections followed by $\mathrm{Ar}$ and $\mathrm{N}_{2}$. Molecules with narrow absorption lines, such as methane and methanol, show strong dependence on bath gas than molecules with relatively broader absorption features i.e. ethane and ethylene.
\end{abstract}

Keywords: Methane; Ethane; Ethylene; Methanol; Absorption cross-section; FTIR, HeNe laser 


\section{Introduction}

Laser-based diagnostic techniques are used in a variety of fields to measure the abundance of species of interest. Spectral absorption features span different wavelength regions from ultraviolet (UV) to visible to infrared (IR) and more. The absorption strength of molecules at various wavelengths is governed by molecular structure and oscillator strengths. Chemical species containing a $\mathrm{C}-\mathrm{H}$ bond have a fundamental vibrational mode, known as the $\mathrm{C}-\mathrm{H}$ stretch, in the IR region near $3.3 \mu \mathrm{m}$. Absorption of radiation by this vibrational mode can be readily accessed by helium-neon (HeNe) lasers or difference-frequency-generation (DFG) based tunable laser systems $[1,2]$. These two laser systems can be used to develop fast time-response in-situ diagnostics to detect various hydrocarbons. For example, MacDonald et al. [3] used HeNe laser absorption at $3.392 \mu \mathrm{m}$ to measure fuel concentration during the pyrolysis of $\mathrm{n}$-dodecane, methylcyclohexane, and iso-cetane in a heated high-pressure shock tube. The species studied in this work (methane, ethane, ethylene and methanol) represent three different chemical groups: alkanes, alkenes and alcohol. These basic species are very important in combustion, atmospheric applications and remote sensing.

Quantitative measurements of species concentration using absorption spectroscopy require knowledge of absolute absorption cross-sections. The cross-sections of various hydrocarbons near $3.3 \mu \mathrm{m}$ have previously been measured using FTIR spectrometer and $\mathrm{HeNe}$ laser. Klingbeil et al. [4] used an FTIR spectrometer to measure the spectra of twelve hydrocarbons over $2500-3400 \mathrm{~cm}^{-1}$ region for temperatures ranging from 298 to $773 \mathrm{~K}$. Essabbar et al. [5, 6] measured vacuum-UV and IR spectra of 1-butene and IR spectra of propylene in the temperature range of $296-529 \mathrm{~K}$. Etzkorn et al. [7] measured UV and IR absorption cross-sections of 24 aromatic hydrocarbons at $298 \mathrm{~K}$ for atmospheric applications. The infrared 
absorption cross-sections of ethane and methanol were reported by Harrison et al. [8, 9] at 296 K. Also, Harrison and Bernath [10] measured the infrared absorption cross-section of propane at 296 K. Furthermore, several databases have been compiled for hydrocarbon spectra, such as HITRAN [11], NIST [12] and PNNL [13]. The HITRAN database has primarily been validated at low temperatures and its high-temperature version HITEMP only contains $\mathrm{H}_{2} \mathrm{O}, \mathrm{CO}_{2}, \mathrm{CO}$, NO, and OH spectra. The NIST and PNNL databases provide absorption cross-sections of many species at low temperatures (up to $50{ }^{\circ} \mathrm{C}$ ). For several important hydrocarbons, such as methane and ethylene, absorption cross-section data are not available at temperatures larger than $500{ }^{\circ} \mathrm{C}$. High-temperature cross-section data are critical for developing laser-based sensors for combustion applications.

Although FTIR spectrometer can measure cross-section data over a range of wavelengths, HeNe laser has the advantages of narrow line-width, low cost and ease of operation. Olson et al. [14] reported the absorption coefficient of 7 hydrocarbon fuels in the temperature range of 300$2000 \mathrm{~K}$ using a shock tube. Mallard and Gardiner [15] studied the absorption cross-section of methane from 300 to $2400 \mathrm{~K}$ using a shock tube. Tsuboi et al. [16] used a shock tube facility to measure the molar extinction coefficients of different hydrocarbons over 292-1100 K. Perrin and Hartmann [17] measured the absorption of methane in the temperature range of $290-800 \mathrm{~K}$ and then reported the calculated absorptivity up to $3000 \mathrm{~K}$. Drallmeier measured room-temperature (296 K) absorption coefficient of different hydrocarbon species; paraffins, olefins and aromatics [18]. The dependence of absorption cross-sections on temperature (298 to $673 \mathrm{~K})$ and pressure (500 to 2000 Torr) at $3.39 \mu \mathrm{m}$ for different gaseous hydrocarbons was investigated by Klingbeil et al. [19]. Mevel et al. [20] reported the gas phase absorption cross-sections of 21 liquid hydrocarbons in the temperature range of $303-413 \mathrm{~K}$ and suggested a correlation to calculate the 
absorption cross-section based on the chemical structure of species. The dependence of the crosssections on bath gas has not been studied well before. Therefore, the cross-sections dependence on the argon, helium and nitrogen are studied in this work.

In this work, we report the spectra of methane, ethane, ethylene and methanol at high temperatures $(296-1120 \mathrm{~K})$ over 2800 to $3400 \mathrm{~cm}^{-1}(2.9-3.6 \mu \mathrm{m})$ region. This wavelength region is important due to relatively high absorption strengths and is accessible by $\mathrm{HeNe}$ laser $(3.392 \mu \mathrm{m})$ or tunable difference-frequency-generation (DFG) laser systems. Therefore, these measured high-temperature spectra are needed to design interference-free quantitative absorption diagnostics for combustion applications. Effect of instrument broadening is considered by comparing measurements performed by FTIR spectrometer with HeNe laser. Additionally, the effect of bath gases on absorption cross-sections is analyzed by performing measurements in argon, helium and nitrogen.

\section{Experimental Setup}

Experimental setup used in this work is shown in Fig. 1. Fourier Transform Infrared (FTIR) spectrometer is a valuable device to measure absorption cross-sections over a wide range of wavelengths. The FTIR spectrometer used is Bruker VERTEX 80v and its broadband beam is modulated through the Michelson interferometer. This modulated beam passes through a heated cell and is detected by the detector. The FTIR can operate over 700 to $8000 \mathrm{~cm}^{-1}$ with a minimum spectral resolution of $0.08 \mathrm{~cm}^{-1}$. Table 1 lists the operating conditions of the FTIR used in this work. In all measurements, a reference/baseline signal is recorded when the cell is evacuated and the transmitted signal is recorded after sample is introduced in the cell. Another reference/baseline signal is recorded after pumping out the sample from the cell. The difference 
between the baseline before and after the sample measurement is generally quite small. In this work, the FTIR wavelength was calibrated for each hydrocarbon with the corresponding spectra from Sharpe et al. [13] at $298 \mathrm{~K}$.

Fixed-wavelength measurements were carried out using a helium-neon ( $\mathrm{HeNe})$ laser $(2.0$ mW, Newport, R-32172). Its center wavenumber was measured by Bristol Spectrum Analyzer and found to be at $2947.909 \mathrm{~cm}^{-1}$, as suggested by Mallard and Gardiner [15]. Spectral resolution of the HeNe laser is approximately $0.01 \mathrm{~cm}^{-1}$ (FWHM). Common-mode-rejection (CMR) scheme is used to account for laser intensity fluctuations. A calcium-fluoride beam splitter is used to direct part of the beam to the reference detector 1 (Vigo Systems, PVMI-3TE-10.6, $2 \mathrm{~mm}$ x $2 \mathrm{~mm}$ active area) while the rest of the beam is transmitted to detector 2 which is identical to detector 1. An iris is used before each detector to minimize broadband emission from the furnace.

Quartz cell is placed inside a tube furnace (Fisher Scientific, model BlueBird) where the $7.747 \mathrm{~cm}$ long test section is within the uniform temperature region of the furnace. The two outer sections of the quartz cell are evacuated to avoid ambient absorption by $\mathrm{CO}_{2} / \mathrm{H}_{2} \mathrm{O}$ along the laser path. The temperature of the test gas is measured by four equally spaced K-type thermocouples (Omega) along the test section. All measurements at temperatures higher than $650 \mathrm{~K}$ are carried out using the quartz cell. Lower temperature measurements are carried out using a stainless-steel 10-cm long cell. This cell is equipped with a heating jacket and is placed inside the FTIR compartment; details of this cell can be found elsewhere [5].

Pressure of the gas mixture is monitored by two capacitance manometers with full-scale ranges of 20-Torr and 1000-Torr (Baratron MKS 620A). A magnetically-stirred mixing vessel is 
used to prepare mixtures of the hydrocarbons with bath gas. The optical cell is evacuated using a vacuum pump to pressures less than 0.001 Torr, with outgassing rate of less than 0.005 Torr $/ \mathrm{min}$. Three measurements of the cross-section are taken at each temperature and then averaged. All spectra presented in this work are measured at a pressure of 760 Torr $(1 \mathrm{~atm})$. All bath gases (argon, nitrogen and helium) have a purity of $99.999 \%$, while methane, ethane and ethylene have purities of $99.999 \%, 99.9995 \%$ and $99.95 \%$, respectively. All gases were supplied by AHG Gases. Methanol is supplied by Sigma-Aldrich with a purity of $99.8 \%$.

When measuring the absorption cross-section of hydrocarbons at high temperatures, thermal decomposition must be taken into consideration. Chemkin-Pro commercial software with detailed chemical kinetic mechanism of Marinov et al. [21] was used to simulate thermal decomposition of methane, ethane, ethylene, and methanol as a function of temperature. At high temperatures where decomposition of the fuel can occur, the static cell experiments were replaced with flow experiments which reduced the residence time of the gas sample inside the heated quartz cell thereby avoiding the decomposition of fuel. The flow rates were controlled by a combination of inlet and outlet metering valves. Flow experiments were used during the measurements of methane, ethane, ethylene and methanol spectra at temperatures higher than $900 \mathrm{~K}$.

\section{Data Analysis}

Beer-Lambert law describes the absorption of monochromic light passing through a uniform medium:

$$
A_{v}=-\ln \left(\frac{I}{I_{o}}\right)=\sigma_{v} \cdot L \cdot n
$$


where $A_{v}$ is the absorbance, $I_{o}$ is the reference signal, $I$ is the transmitted signal, $\sigma_{v}$ is the absorption cross-section in $\mathrm{cm}^{2} /$ molecule, $\mathrm{L}$ is the optical path length in $\mathrm{cm}$, and $\mathrm{n}$ is the concentration of the gas in $\mathrm{cm}^{-3}$. Absorption cross-section can be calculated by:

$$
\sigma_{\mathrm{v}}=\frac{\mathrm{A}_{\mathrm{v}} \mathrm{kT}}{\mathrm{PL}}
$$

where $\mathrm{k}$ is the Boltzmann's constant $\left(\mathrm{k}=1.38065 \times 10^{-23} \mathrm{~J} / \mathrm{K}\right), P$ is the pressure and $T$ is the temperature of the gas. Integrated band intensity is the integration of the absorption crosssections over an entire vibrational band or over a certain wavelength region. In this work, crosssections are integrated over $2500-3400 \mathrm{~cm}^{-1}$ to calculate the integrated band intensity by:

$$
S_{v}=\int \sigma_{v} d v=\frac{k T}{P L} \int A_{v} d v
$$

Detailed uncertainty analysis is carried out to estimate the errors in the measured absorption cross-section and the integrated band intensity. According to equations (2) and (3), there are five sources of uncertainty: absorbance, mole fraction, temperature, pressure and path length. In this work, absorbance $\left(A_{v}\right)$ values generally varied between 0.2 and 2 which resulted in relatively high signal-to-noise-ratio (SNR). The uncertainty on the absorbance is taken from the standard deviation of the recorded data. The uncertainty on the mole fraction of the fuel is due to the partial pressure of the fuel and the total pressure. The uncertainty of the two pressure gauges (Baratrons) used is $\pm 0.12 \%$ of the reading. To avoid the adsorption of methanol, a liquid fuel, to the walls of the mixing vessel, the partial pressure of methanol is kept at less than half of its saturation vapor pressure at $296 \mathrm{~K}$. The temperature uncertainty comes from the temperature profile in the test section and the uncertainty of the thermocouple readings. The pressure remains almost constant during the experiment and the uncertainty of the test pressure is $\pm 0.12 \%$ of the 
reading. The uncertainty in the path length is due to the expansion of the two optical windows with temperature and the path travelled by the laser beam. The overall uncertainty of the absorption cross-section (or the integrated band intensity) is given by:

$$
\frac{\mathrm{d} \sigma_{\mathrm{v}}}{\sigma_{\mathrm{v}}}\left(\text { or } \frac{\mathrm{d} \mathrm{S}_{\mathrm{v}}}{\mathrm{S}_{\mathrm{v}}}\right)=\sqrt{\left(\frac{\Delta \mathrm{A}}{\mathrm{A}}\right)^{2}+\left(\frac{\Delta \mathrm{X}_{\mathrm{i}}}{\mathrm{X}_{\mathrm{i}}}\right)^{2}+\left(\frac{\Delta \mathrm{T}}{\mathrm{T}}\right)^{2}+\left(\frac{\Delta \mathrm{P}}{\mathrm{P}}\right)^{2}+\left(\frac{\Delta \mathrm{L}}{\mathrm{L}}\right)^{2}}
$$

The uncertainty of the measured absorption cross-section is calculated to be less than $5 \%$ for lower temperatures and about $8 \%$ for temperatures higher than $700 \mathrm{~K}$.

\section{Results and Discussion}

Absorption cross-sections of methane, ethane, ethylene and methanol are reported here over a temperature range of $296-1100 \mathrm{~K}$. The FTIR spectrometer is used to measure spectra over the wavelength range of $2800-3400 \mathrm{~cm}^{-1}$. HeNe laser, operating at $3.932 \mu \mathrm{m}$, is used to measure the absorption cross-section at a fixed frequency. Finally, the effect of bath gas on absorption cross-sections is analyzed by making measurements in helium, argon and nitrogen as bath gases.

\subsection{Temperature-dependent mid-IR spectra}

Absorption cross-sections of methane, measured by the FTIR, are plotted in Figure 2 as a function of temperatures $(296-1120 \mathrm{~K})$ over $2800-3300 \mathrm{~cm}^{-1}$ region. Methane spectra in this region consist of relatively narrow absorption lines and the spectra are dominated by strong absorptions due to the $v_{3} \mathrm{C}-\mathrm{H}$ stretching mode and small contribution from the $v_{2}+v_{4}$ combination band [22]. It can be observed from Fig. 2 that as temperature increases, peak

transition intensity decreases while higher rotational levels get populated and the band continuum increases. As discussed earlier, to ensure methane does not undergo decomposition during high-temperature measurements $(919 \mathrm{~K}, 1120 \mathrm{~K})$, a flow experiment is used to reduce the 
residence time. The FTIR measurements are performed with a spectral resolution of $0.16 \mathrm{~cm}^{-1}$ for low temperature $(\mathrm{T}<500 \mathrm{~K})$ and $0.6 \mathrm{~cm}^{-1}$ for experiments at temperature higher than $500 \mathrm{~K}$. The later resolution was selected to maximize the signal-to-noise ratio for high-temperature measurements where the mid-IR beam was directed through the furnace and had relatively low transmitted intensity.

Figure 3 shows ethane spectra recorded over $2800-3200 \mathrm{~cm}^{-1}$ region by FTIR at five temperature values from 296 to $921 \mathrm{~K}$. The absorption spectra exhibit strong absorption assigned to $v_{7} \mathrm{C}-\mathrm{H}$ stretching mode together with small contribution of $v_{10}$ feature near $2985 \mathrm{~cm}^{-1}$ [22]. Similar to methane, the peak intensities decrease with increasing temperature and the band continuum increase. In the insert of the same figure, ethane spectrum obtained at $296 \mathrm{~K}$ with a resolution of $0.16 \mathrm{~cm}^{-1}$ are compared with the PNNL data measured at $0.112 \mathrm{~cm}^{-1}$ spectral resolution [13]. The two spectra agree very well with each other confirming that the chosen resolution of $0.16 \mathrm{~cm}^{-1}$ is sufficient to resolve various features of ethane spectrum.

Ethylene spectra measured between 2850 and $3250 \mathrm{~cm}^{-1}$ are shown in Fig. 4 as a function of temperature. The $v_{11}$ feature located near $2988 \mathrm{~cm}^{-1}$ [22] is dominant in this region. The gas temperature has the same effect as discussed above for methane and ethane. The change in the peak intensity with temperature is illustrated in the insert of the figure for the $v_{11}$ peak near 2988 $\mathrm{cm}^{-1}$. The cross-sections of ethylene are weaker than ethane because of the replacement of the $\mathrm{C}-\mathrm{H}$ bond by the $\mathrm{C}=\mathrm{C}$ bond.

The measured absorption cross-sections of methanol in the spectral range of $2750-3400$ $\mathrm{cm}^{-1}$ are presented in Fig. 5 as a function of temperature $(296-778 \mathrm{~K})$. Recently, high-resolution $\left(0.015 \mathrm{~cm}^{-1}\right)$ absorption spectra of methanol were measured near $3.3 \mu \mathrm{m}$ at low temperatures 
$(204-296 \mathrm{~K})$ by Harrison et al. [9]. There are three fundamental vibrational modes in this region which are $v_{2}, v_{3}$ and $v_{9}$ with values of 2999,2844 and $2970 \mathrm{~cm}^{-1}$, respectively [22]. Absorption cross-sections of methanol are weaker than methane due to the replacement of the C$\mathrm{H}$ bond with the $\mathrm{C}-\mathrm{O}$ one. However, methanol spectrum is relatively broad due to the contribution of neighboring bands of methanol.

\section{2 . Integrated band intensities}

Since absorption cross-sections are measured as a function of temperature at two spectral resolutions $\left(0.16\right.$ and $\left.0.6 \mathrm{~cm}^{-1}\right)$, it is interesting to discuss our results in terms of the integrated intensities. The integrated intensities of the four studied hydrocarbons over the spectral region $2500-3400 \mathrm{~cm}^{-1}$ are listed in Table 2 at $296 \mathrm{~K}$. The obtained results are compared with data available in the literature. Our values are in good agreement with previous measurements of Sharpe et al. [13], Klingbeil [23], and Harrison et al. [8, 9] with a maximum difference of about $6 \%$. The integrated band intensity of ethane is higher than methane since the band intensity for alkanes increases as the number of the $\mathrm{C}-\mathrm{H}$ bonds increases [24]. Ethylene has lower integrated band intensity due to the replacement of $\mathrm{C}-\mathrm{H}$ bonds with $\mathrm{C}=\mathrm{C}$ double bond. Although the peak absorption cross-section of methanol is lower than methane, it has higher integrated band intensity due to the overall broader spectrum that results from additional vibrational modes.

The integrated band intensities are also calculated at higher temperatures and are presented in Table 3. Over the studied temperature range, the band intensities vary by about $10 \%, 12 \%, 7 \%$, and $1 \%$ for methane, ethane, ethylene and methanol, respectively. It cannot be said conclusively whether the integrated band intensities exhibit slight temperature dependence or if the observed variations are the result of experimental uncertainties. It has been reported 
previously $[6,25,26]$ that the band intensities of fundamental vibrational bands can exhibit small temperature dependence because of the overlap from other bands.

The effect of spectral resolution on the integrated band intensities is also studied. Methane spectra at conditions similar to this work were simulated using HITRAN [11] database and a Voigt profile with spectra resolution of $0.01 \mathrm{~cm}^{-1}$; integrated band intensities are compared in Table 4. Even though the spectra from HITRAN have higher resolution $\left(0.01 \mathrm{~cm}^{-1}\right)$ than the

measurements $\left(0.16\right.$ or $\left.0.6 \mathrm{~cm}^{-1}\right)$ reported here, the integrated band intensities are in good agreement with a maximum difference of $8.7 \%$ at the highest temperature. This difference at the highest temperature could be because of hot band transitions not included in the HITRAN database. In another work on spectral measurements of propylene $\left(\mathrm{C}_{3} \mathrm{H}_{6}\right)$, it was demonstrated that the integrated band intensities at various spectral resolutions were within $2 \%$ of each other [6].

\section{3 . Bath gas dependent absorption cross-sections at $3.392 \mu \mathrm{m}$}

A helium-neon ( $\mathrm{HeNe}$ ) laser is used to measure the absorption cross-sections at $3.392 \mu \mathrm{m}$ for methane, ethane, ethylene and methanol with three bath gases (argon, nitrogen and helium). Figure 6 shows the absorption cross-sections of methane measured over a temperature range of $296-1045 \mathrm{~K}$ and pressure near 760 Torr. Our measured values are compared with previous measurements by Klingbeil et al. [19] Perrin and Hartmann [17], Tsuboi et al. [16], Harrison et al. [8, 9] and Olson et al. [14] using HeNe laser at temperatures less than $600 \mathrm{~K}$. As expected, the absorption cross-sections decrease with increasing temperature as the population in ground state reduces. 
Absorption cross-sections of methane show dependence on bath gas at relatively low temperatures (less than $400 \mathrm{~K}$ ). To further investigate the effect of bath gas on methane crosssections, series of measurements were conducted at $296 \mathrm{~K}$ and varying total pressure (200 - 1000 Torr). Results are shown in Fig. 7 for $1 \% \mathrm{CH}_{4}$ in $\mathrm{He}, \mathrm{Ar}$, and $\mathrm{N}_{2}$. The measured cross-sections exhibit pressure dependence as methane has relatively narrow absorption features. For example, the cross-section decreases by a factor of 2 when increasing the pressure from 200 to 1000 Torr in $\mathrm{CH}_{4} / \mathrm{Ar}$ mixture. At all pressures, the mixture of methane with helium has the highest crosssection, followed by $\mathrm{CH}_{4} / \mathrm{Ar}$ and $\mathrm{CH}_{4} / \mathrm{N}_{2}$ mixtures. This trend is observed because absorption cross-section is inversely related to the collisional broadening coefficient. The HeNe laser measurements are carried out at a frequency of $2947.909 \mathrm{~cm}^{-1}$ which is quite close to the linecenter frequency, $2947.912 \mathrm{~cm}^{-1}$, of the $\mathrm{P}(7)$ rotational transition of methane. For the $\mathrm{P}(7)$ transition, the collisional broadening coefficients $(\gamma)$ of $\mathrm{CH}_{4}-\mathrm{He}, \mathrm{CH}_{4}-\mathrm{Ar}$ and $\mathrm{CH}_{4}-\mathrm{N}_{2}$ at $296 \mathrm{~K}$ are 0.048 [15], 0.056 [27] and 0.063 [27] $\mathrm{cm}^{-1} / \mathrm{atm}$, respectively. This dependence of methane cross-section on bath gases was also reported by Tsuboi et al. [28] in their theoretical study. In their calculations, the absorption cross-section of $\mathrm{CH}_{4}-\mathrm{N}_{2}$ mixture is less by $35 \%$ and $10 \%$ compared to absorption cross-sections of $\mathrm{CH}_{4}-\mathrm{He}$ and $\mathrm{CH}_{4}-\mathrm{Ar}$ mixtures, respectively. Our experimental measurements show the corresponding decrease to be $28 \%$ and $10 \%$.

Absorption cross-sections of methanol measured by HeNe laser are shown in Fig. 8 as a function of temperature and bath gas. Our results agree very well with the data of Tsuboi et al. [16]. The cross-section decreases with increasing temperature though the drop is much sharper at lower temperatures $(<500 \mathrm{~K})$. Methanol absorption cross-sections exhibit similar dependence on bath gas as was observed for methane. At temperatures less than $600 \mathrm{~K}$, methanol/He mixture has the highest cross-section followed by methanol/Ar and methanol/ $\mathrm{N}_{2}$ mixtures. 
Figure 9 shows the absorption cross-sections of ethylene, measured with HeNe laser, as a function of temperature and bath gas. Relatively large ethylene concentration $(10-40 \%)$ is used for these measurements since the ethylene absorption is relatively weak at the $\mathrm{HeNe}$ laser wavelength. As observed previously by Klingbeil et al. [19], the absorption cross-section of ethylene increases with temperature at the HeNe laser wavelength $\left(2947.909 \mathrm{~cm}^{-1}\right)$. This is due to the fact that this wavelength is close to a hot band transition and its intensity increases with increasing temperatures. Ethylene shows relatively less dependence on bath gas compared to methane and methanol. However, it is clear from the high-temperature $(>600 \mathrm{~K})$ data that the cross-section is larger for helium mixture followed by argon and nitrogen mixtures.

Absorption cross-sections of ethane, measured by HeNe laser, are shown in Fig. 10 as a function of temperature and bath gas. Our measured values agree with Harrison et al. [8] and Olson et al. [14] data but Tsuboi et al. [16] value appears to be lower by about $10 \%$. The crosssections show very little temperature dependence because the HeNe laser emission wavelength is close to the inflexion region (between the peak and valley) which is known to exhibit very little variation with temperature. For the same reason, the cross-sections of ethane do not exhibit appreciable dependence on the bath gas. The same phenomenon was observed in another study carried out in our laboratory for propane, propylene and ethanol (data not shown here) where their cross-sections did not show any dependence on the bath gas.

The values of the cross-sections, measured by HeNe laser, at room temperature (296 K) and atmospheric pressure (760 Torr) are summarized in Table 5 for different bath gases. As observed from Figs. $6-10$, Table 5 also demonstrates that methane and methanol exhibit relatively strong dependence on bath gas. Since ethane and ethylene have a broad feature near the HeNe laser wavelength, their cross-sections show very little variation with bath gas. 


\section{Conclusions}

Mid-IR absorption cross-sections were measured for methane, ethane, ethylene and methanol using an FTIR spectrometer and a fixed-wavelength HeNe laser. The studied fuels belong to three different chemical groups: alkanes, alkenes and alcohol and are very important in combustion and atmospheric kinetics. The temperature range of this study is $296-1120 \mathrm{~K}$ and the spectral region spans 2800 to $3400 \mathrm{~cm}^{-1}$. The spectra of all studied fuels exhibit the expected trend of decreasing peak intensity and increasing wings of the spectrum as temperature increases. On the other hand, the integrated band intensities are found to be nearly independent of temperature. Measurements with HeNe laser are used to understand the variation of absorption cross-section at a specific wavelength with temperature and bath gas Methane and methanol cross-sections exhibit dependence on bath gas whereas this dependence is very weak for ethane and ethylene. This work has extended the temperature range of absorption cross-sections for these fuels compared to previous works. The spectra and absorption cross-sections reported here will prove quite useful in developing high-temperature laser-based diagnostics. 
Tables

Table 1. FTIR settings used to measure mid-IR spectra of methane, ethane, ethylene and methanol.

\begin{tabular}{|c|c|}
\hline \multirow{2}{*}{ Resolution } & $0.16 \mathrm{~cm}^{-1}(\mathrm{~T}<500 \mathrm{~K})$ \\
\cline { 2 - 2 } & $0.6 \mathrm{~cm}^{-1}(\mathrm{~T}>500 \mathrm{~K})$ \\
\hline Beamsplitter & Potassium bromide $(\mathrm{KBr})$ \\
\hline Input aperture & $2.5 \mathrm{~mm}$ \\
\hline Detector & DigiTect DLaTGS \\
\hline Light Source & Globar (Mid-infrared) \\
\hline FT phase correction, zero fill & Mertz, 2 x zero-filling \\
\hline
\end{tabular}


Table 2. Integrated band intensities $\left(2500-3400 \mathrm{~cm}^{-1}\right)$ at $296 \mathrm{~K}$ and comparison with previous studies. The $\%$ difference is calculated as: $\% \delta=100 \times\left|\frac{S_{\text {this work }}-S_{\text {others }}}{S_{\text {this work }}}\right|$.

\begin{tabular}{|c|c|c|c|c|c|c|c|}
\hline \multirow{2}{*}{ Molecule } & \multirow{2}{*}{$\begin{array}{c}\text { This Work } \\
(296 \mathrm{~K}) \\
x^{-17} \\
\text { cm/molecule }\end{array}$} & \multicolumn{2}{|c|}{$\begin{array}{c}\text { Sharpe et al. [13] } \\
(298 \mathrm{~K})\end{array}$} & \multicolumn{2}{|c|}{$\begin{array}{c}\text { Klingbeil [23] } \\
\qquad(298 \mathrm{~K})\end{array}$} & \multicolumn{2}{|c|}{$\begin{array}{l}\text { Harrison et al. [8] } \\
\qquad(298 \mathrm{~K})\end{array}$} \\
\hline & & $\begin{array}{c}{\mathrm{x} 10^{-17}} \\
\mathrm{~cm} / \mathrm{molecule}\end{array}$ & $\% \delta$ & $\begin{array}{c}\mathrm{x10}^{-17} \\
\mathrm{~cm} / \mathrm{molecule}\end{array}$ & $\% \delta$ & $\begin{array}{c}\mathrm{x10}^{-17} \\
\mathrm{~cm} / \mathrm{molecule}\end{array}$ & $\% \delta$ \\
\hline Methane & $1.11( \pm 0.06)$ & 1.10 & 0.9 & 1.18 & 6.31 & -- & -- \\
\hline Ethane & $2.81( \pm 0.14)$ & 2.84 & 1.07 & 2.81 & 0.00 & 2.94 & 4.63 \\
\hline Ethylene & $0.70( \pm 0.04)$ & 0.69 & 1.43 & 0.72 & 2.86 & --- & --- \\
\hline Methanol & $2.17( \pm 0.11)$ & 2.04 & 5.99 & - & --- & --- & --- \\
\hline
\end{tabular}


Table 3. Integrated band intensities $\left(2500-3400 \mathrm{~cm}^{-1}\right)$ at various temperatures.

\begin{tabular}{|c|c|c|c|c|}
\hline $\mathbf{T}(\mathbf{K})$ & $\begin{array}{c}\text { Methane (x10 } \\
\text { cm/molecule) }\end{array}$ & $\begin{array}{l}\text { Ethane (x10 } \\
\text { cm/molecule) }\end{array}$ & $\begin{array}{c}\text { Ethylene (x10 } \\
\text { cm/molecule) }\end{array}$ & $\begin{array}{c}\text { Methanol (x10-17 } \\
\text { cm/molecule) }\end{array}$ \\
\hline 296 & $1.11( \pm 0.06)$ & $2.81( \pm 0.14)$ & $0.70( \pm 0.04)$ & $2.17( \pm 0.11)$ \\
\hline 373 & $1.17( \pm 0.6)$ & $2.98( \pm 0.15)$ & $0.69( \pm 0.03)$ & $2.15( \pm 0.11)$ \\
\hline 523 & $1.21( \pm 0.06)$ & $3.01( \pm 0.15)$ & $0.71( \pm 0.04)$ & $2.16( \pm 0.11)$ \\
\hline 673 & $1.04( \pm 0.05)$ & $2.99( \pm 0.18)$ & $0.72( \pm 0.03)$ & $2.17( \pm 0.13)$ \\
\hline 773 & $1.04( \pm 0.08)$ & $3.08( \pm 0.25)$ & $0.74( \pm 0.06)$ & $2.17( \pm 0.17)$ \\
\hline 920 & $1.01( \pm 0.08)$ & $3.15( \pm 0.25)$ & $0.75( \pm 0.06)$ & --- \\
\hline 1060 & $1.22( \pm 0.09)$ & --- & --- & --- \\
\hline 1120 & $1.21( \pm 0.09)$ & --- & --- & --- \\
\hline
\end{tabular}


Table 4. Comparison between the integrated band intensities $\left(2500-3400 \mathrm{~cm}^{-1}\right)$ of methane from HITRAN and this work at various temperatures. The unit of the integrated band intensity is $\left(x_{10}^{-17} \mathrm{~cm} / \mathrm{molecule}\right)$.

\begin{tabular}{|c|c|c|c|}
\hline $\mathbf{T}(\mathbf{K})$ & This Work & $\begin{array}{c}\text { HITRAN }^{\mathrm{a}} \\
\text { (resolution } 0.01 \mathrm{~cm}^{-1} \text { ) }\end{array}$ & Difference, $\%$ \\
\hline 296 & $\begin{array}{c}1.11 \\
\left(\text { resolution } 0.16 \mathrm{~cm}^{-1} \text { ) }\right.\end{array}$ & 1.11 & 0.0 \\
\hline 373 & $\begin{array}{c}1.17 \\
\left(\text { resolution } 0.16 \mathrm{~cm}^{-1} \text { ) }\right.\end{array}$ & 1.11 & 5.1 \\
\hline 673 & $\begin{array}{c}1.04 \\
\text { (resolution } 0.6 \mathrm{~cm}^{-1} \text { ) }\end{array}$ & 1.03 & 1.0 \\
\hline 773 & $\begin{array}{c}1.04 \\
\text { (resolution } 0.6 \mathrm{~cm}^{-1} \text { ) }\end{array}$ & 0.95 & 8.7 \\
\hline
\end{tabular}


Table 5. Variation of the measured absorption cross-sections, using HeNe laser (3392 nm), with helium, argon and nitrogen as bath gases at $296 \mathrm{~K}$ and 1 atm.

\begin{tabular}{|c|c|c|c|c|c|}
\hline \multirow{2}{*}{ Species } & \multicolumn{2}{|c|}{ Absorption Cross-section $\left(\mathbf{x}^{2}{ }^{-19} \mathbf{c m}^{2} /\right.$ molecule $)$} & \multicolumn{2}{c|}{ difference } \\
& \multicolumn{2}{|c|}{ Aross-section } \\
\cline { 2 - 6 } & Helium & Argon & Nitrogen & He- $\mathbf{N}_{2}$ & Ar- $\mathbf{N}_{2}$ \\
\hline Methane & $4.39( \pm 0.22)$ & $3.81( \pm 0.18)$ & $3.45( \pm 0.17)$ & $\mathbf{2 7 . 4 1}$ & $\mathbf{1 0 . 4 3}$ \\
\hline Methanol & $1.43( \pm 0.07)$ & $1.42( \pm 0.07)$ & $1.28( \pm 0.07)$ & $\mathbf{1 2 . 0 8}$ & $\mathbf{1 0 . 7 8}$ \\
\hline Ethylene & $0.075( \pm 0.003)$ & $0.073( \pm 0.003)$ & $0.073( \pm 0.003)$ & $\mathbf{2 . 2 7}$ & $\mathbf{0 . 0 0}$ \\
\hline Ethane & $1.71( \pm 0.10)$ & $1.69( \pm 0.08)$ & $1.68( \pm 0.08)$ & $\mathbf{1 . 6 8}$ & $\mathbf{0 . 6 9}$ \\
\hline
\end{tabular}




\section{Figure Captions}

Figure 1. Schematic of the experimental setup: a) FTIR and HeNe laser setups. b) Detailed arrangement of the quartz cell.

Figure 2. FTIR-measured spectra of methane showing the origin of the $v_{3}$ band and the P, Q, R branches. Methance concentration ranged from 0.5 to $10 \%\left(\right.$ in $_{2}$ ) for different temperatures.

Figure 3. FTIR-measured spectra of ethane showing the origin of the $v_{1}, v_{7}$ and $v_{10}$ bands. Ethane concentration ranged from 1 to $10 \%$ (in $\mathrm{N}_{2}$ ) for different temperatures. A comparison between this work and Sharpe et al. [13] is shown the upper-right corner at $296 \mathrm{~K}$.

Figure 4. FTIR-measured spectra of ethylene showing the origin of the $v_{11}$ and $v_{9}$ bands. Ethylene concentration ranged from 10 to $40 \%$ (in $\mathrm{N}_{2}$ ) for different temperatures. The insert shows a zoomed-in view of the temperature dependence of the $v_{11}$ peak.

Figure 5. FTIR-measured spectra of methanol showing the origin of the $v_{2}, v_{3}$ and $v_{9}$ bands. Ethylene concentration ranged from 1.5 to $6 \%\left(\right.$ in $\mathrm{N}_{2}$ ) for different temperatures.

Figure 6. Absorption cross-sections of methane, measured by HeNe laser (3392 nm), with different bath gases.

Figure 7. Bath gas dependent absorption cross-sections of methane with $\mathrm{Ar}, \mathrm{He}$ and $\mathrm{N}_{2}$ at $296 \mathrm{~K}$. Measurements carried out with HeNe laser at $3.392 \mu \mathrm{m}$.

Figure 8. Absorption cross-sections of methanol, measured by HeNe laser (3392 nm), showing dependence on the bath gases ( $\mathrm{Ar}, \mathrm{He}$ and $\mathrm{N}_{2}$ ).

Figure 9. Absorption cross-sections of ethylene, measured by $\mathrm{HeNe}$ laser (3392 nm), as a function of temperature and bath gas $\left(\mathrm{He}, \mathrm{Ar}, \mathrm{N}_{2}\right)$. 
Figure 10. Absorption cross-sections of ethane, measured by HeNe laser (3392 nm), as a function of bath gases (He, $\left.\mathrm{Ar}, \mathrm{N}_{2}\right)$. 
Figure 1. Schematic of the experimental setup: a) FTIR and HeNe laser setups. b) Detailed arrangement of the quartz cell.

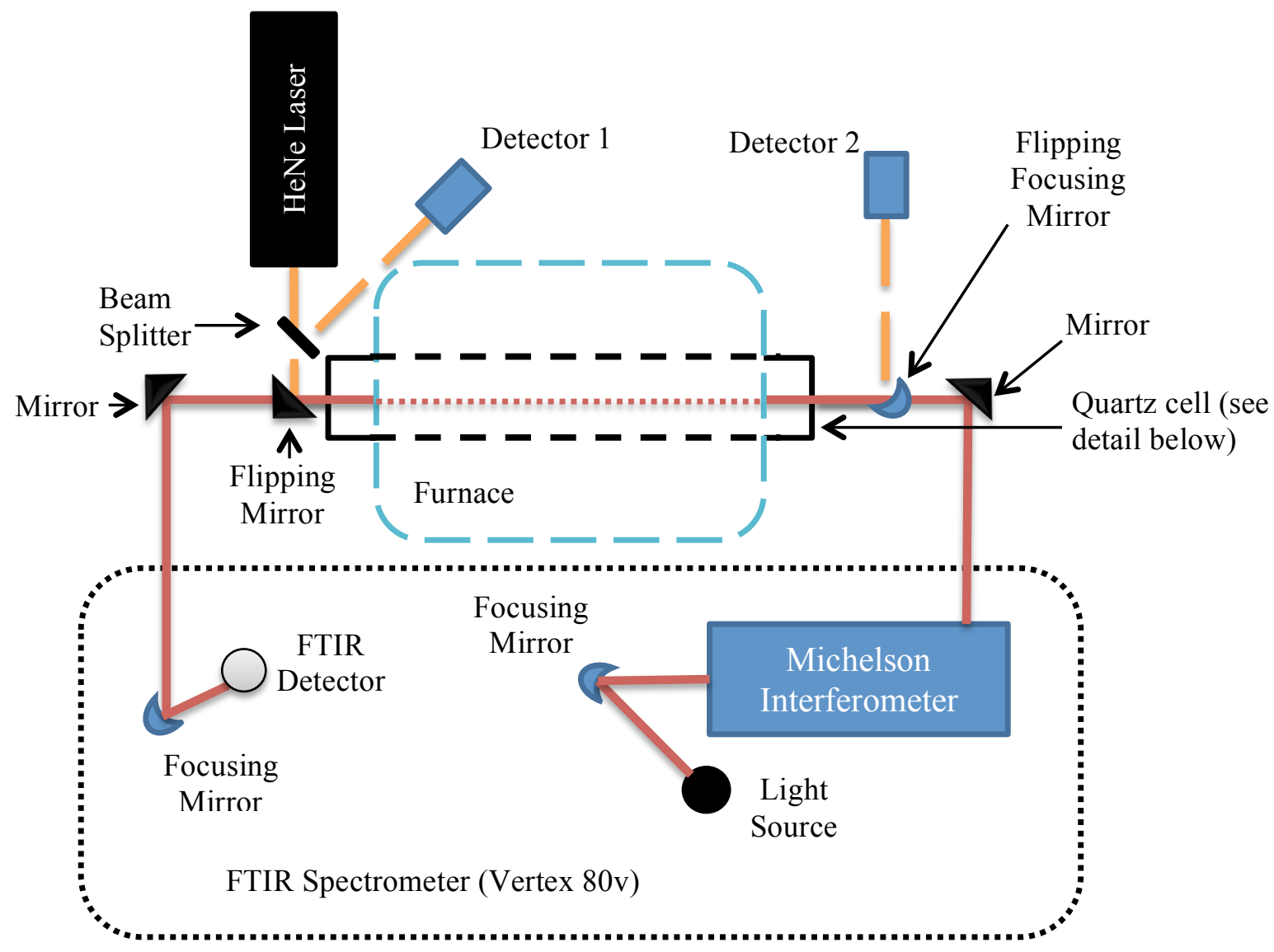

a) FTIR and HeNe laser setup

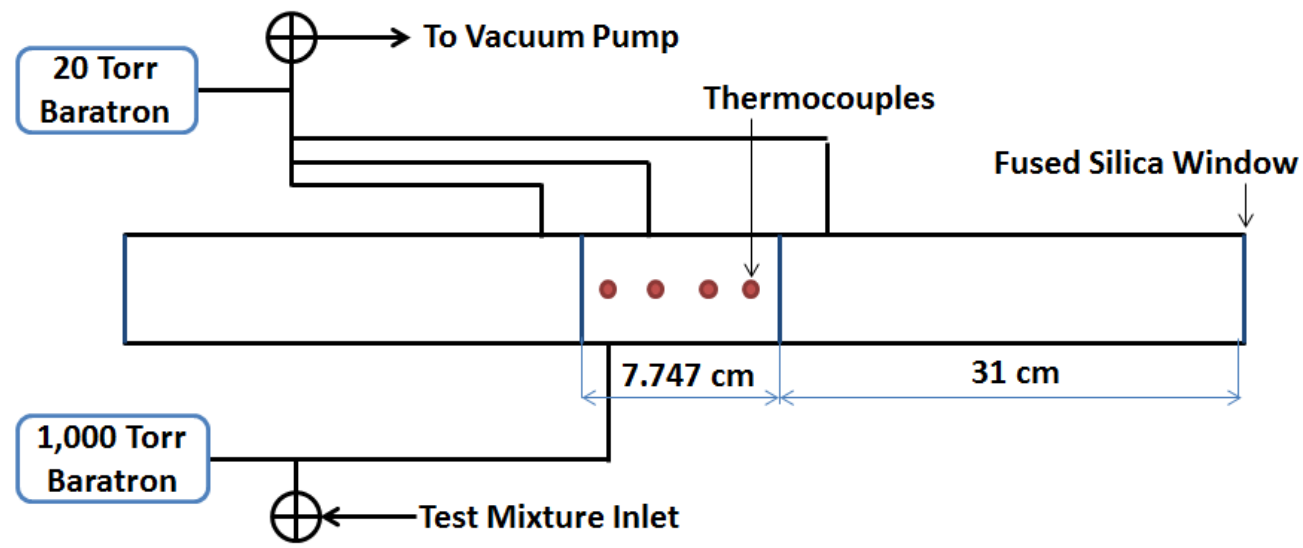

b) Quartz cell 
Figure 2. FTIR-measured spectra of methane showing the origin of the $v_{3}$ band and the P, Q, R branches. Methance concentration ranged from 0.5 to $10 \%\left(\right.$ in $\left.\mathrm{N}_{2}\right)$ for different temperatures.

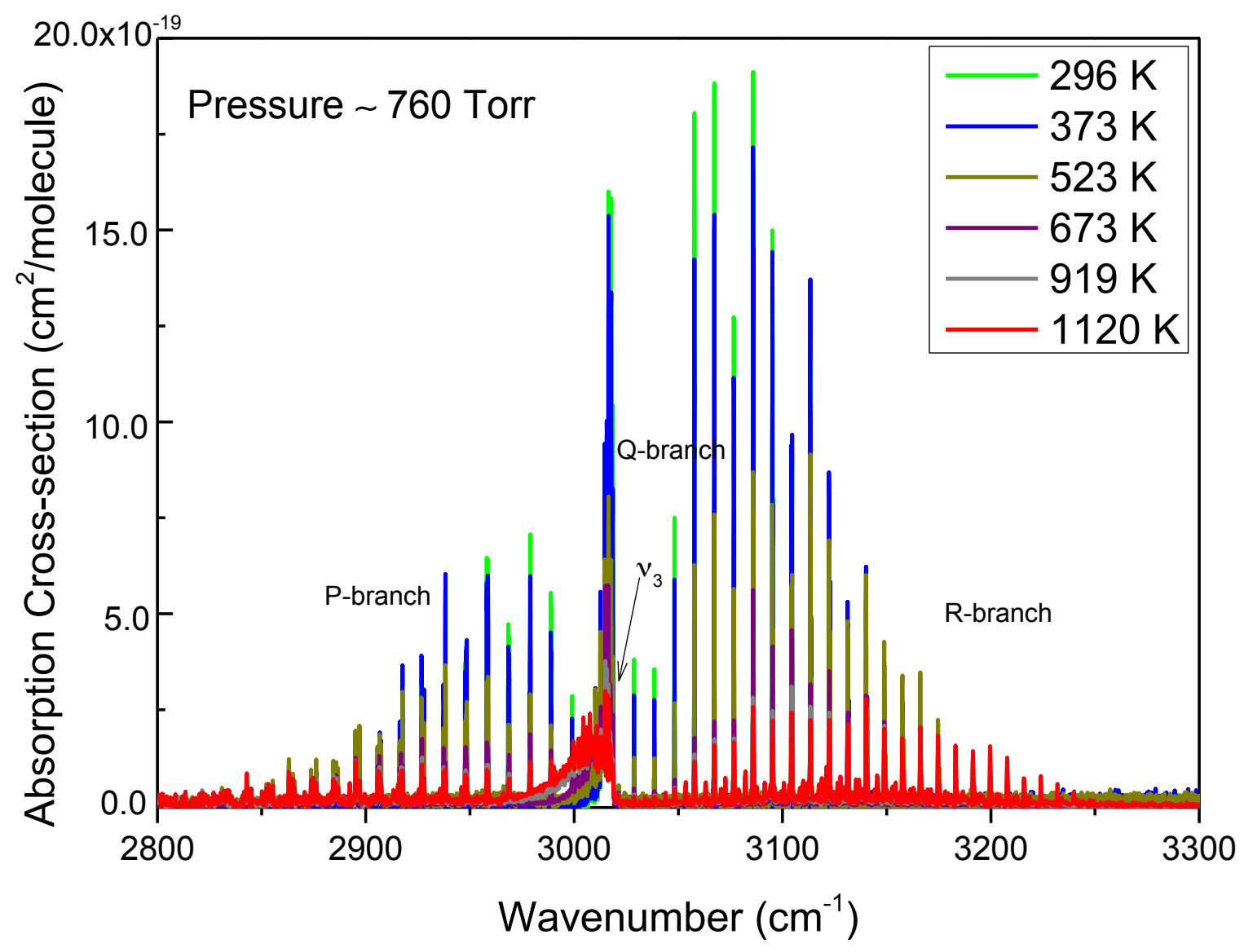


Figure 3. FTIR-measured spectra of ethane showing the origin of the $v_{1}, v_{7}$ and $v_{10}$ bands.

Ethane concentration ranged from 1 to $10 \%$ (in $\mathrm{N}_{2}$ ) for different temperatures. A comparison between this work and Sharpe et al. [13] is shown the upper-right corner at $296 \mathrm{~K}$.

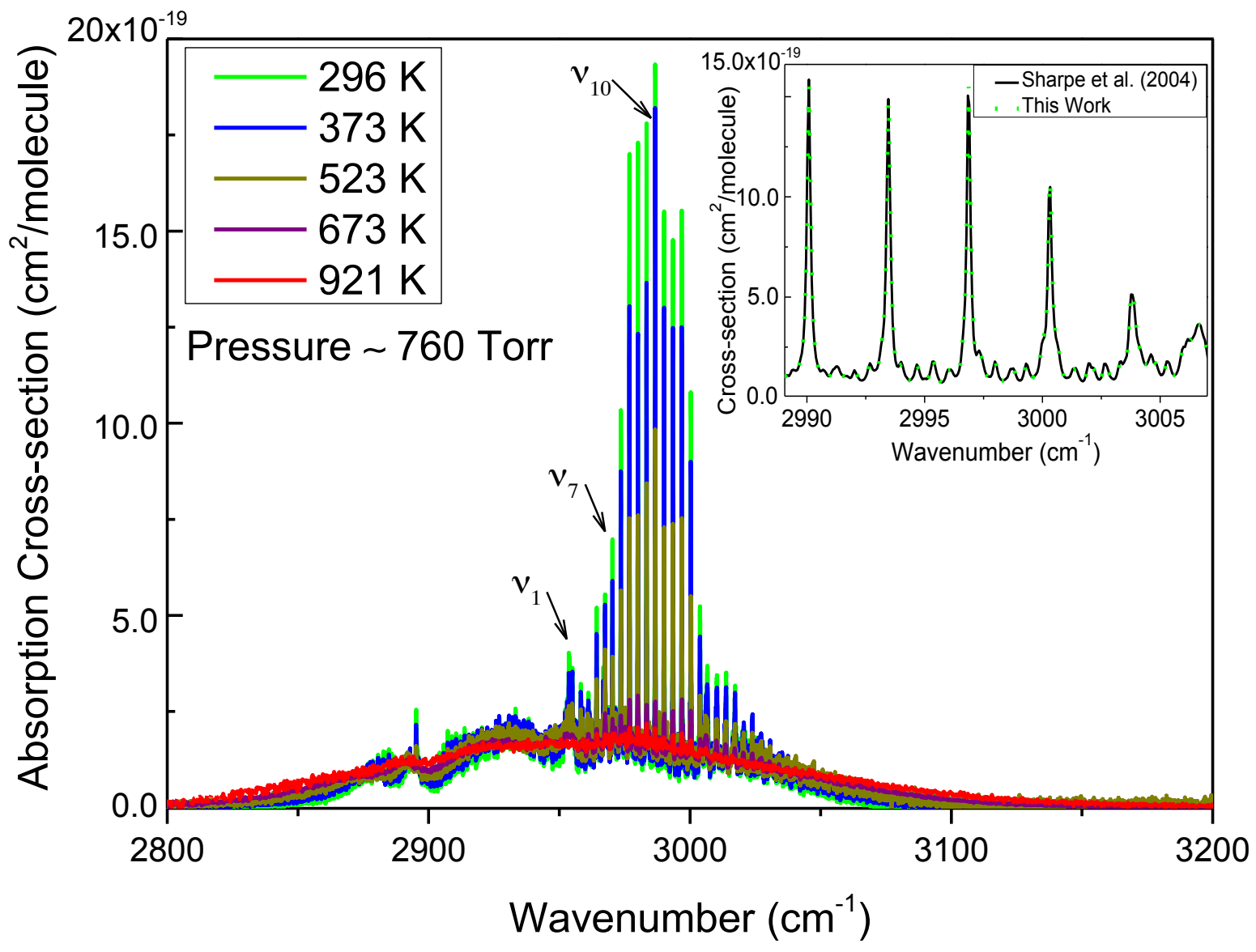


Figure 4. FTIR-measured spectra of ethylene showing the origin of the $v_{11}$ and $v_{9}$ bands.

Ethylene concentration ranged from 10 to $40 \%$ (in $\mathrm{N}_{2}$ ) for different temperatures. The insert shows a zoomed-in view of the temperature dependence of the $v_{11}$ peak.

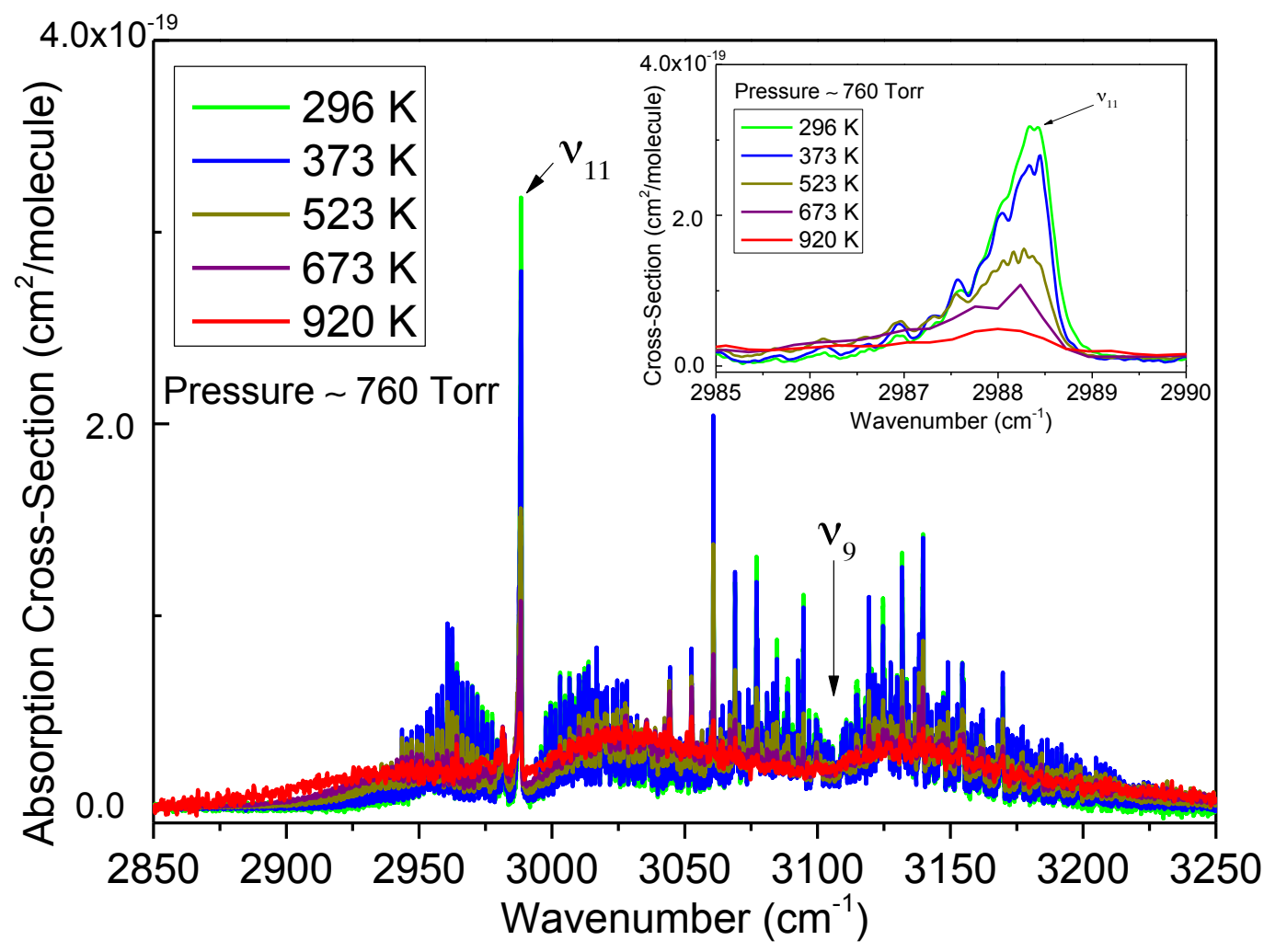


Figure 5. FTIR-measured spectra of methanol showing the origin of the $v_{2}, v_{3}$ and $v_{9}$ bands. Methanol concentration ranged from 1.5 to $6 \%\left(\right.$ in $\mathrm{N}_{2}$ ) for different temperatures.

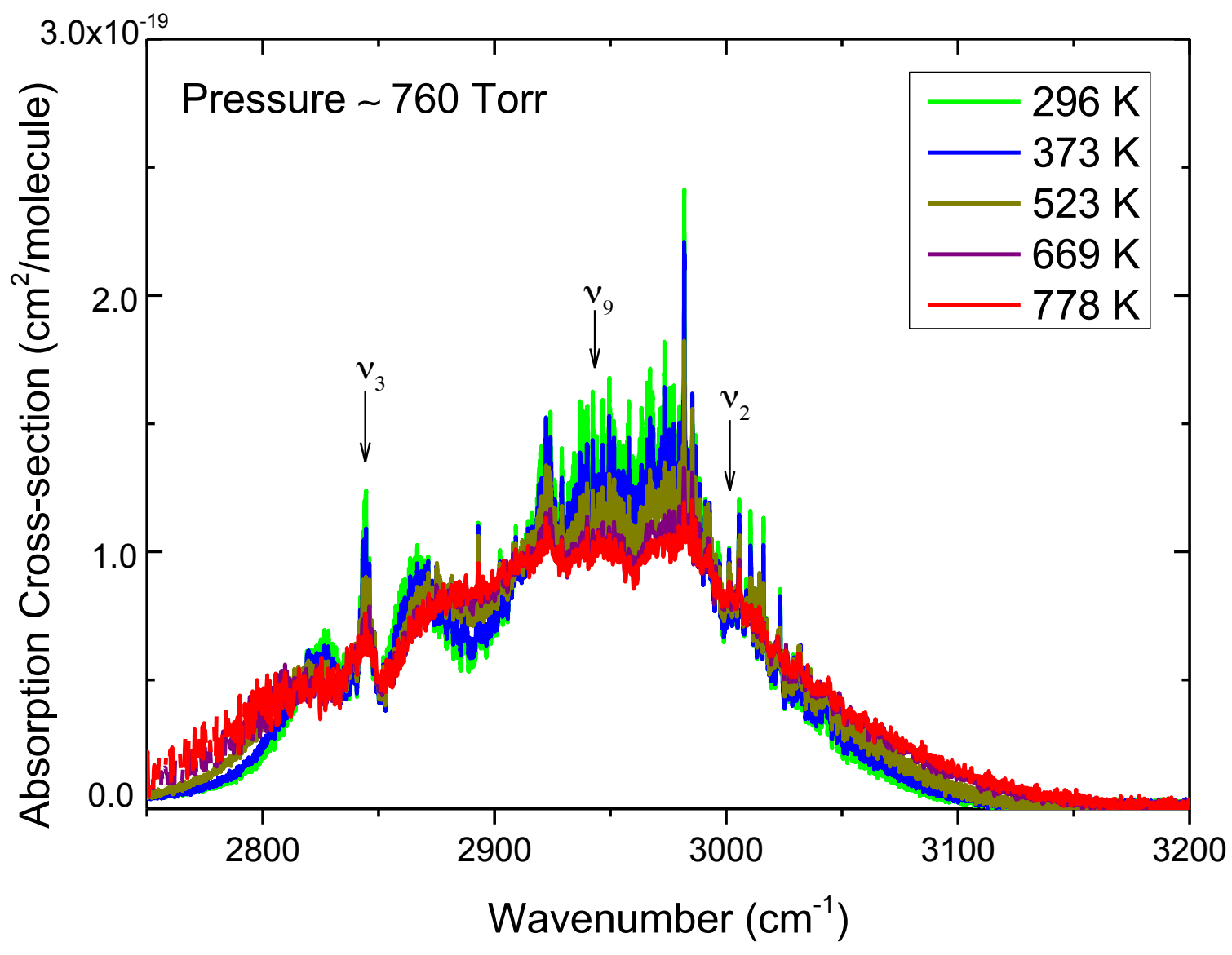


Figure 6. Absorption cross-sections of methane, measured by HeNe laser (3392 nm), with different bath gases.

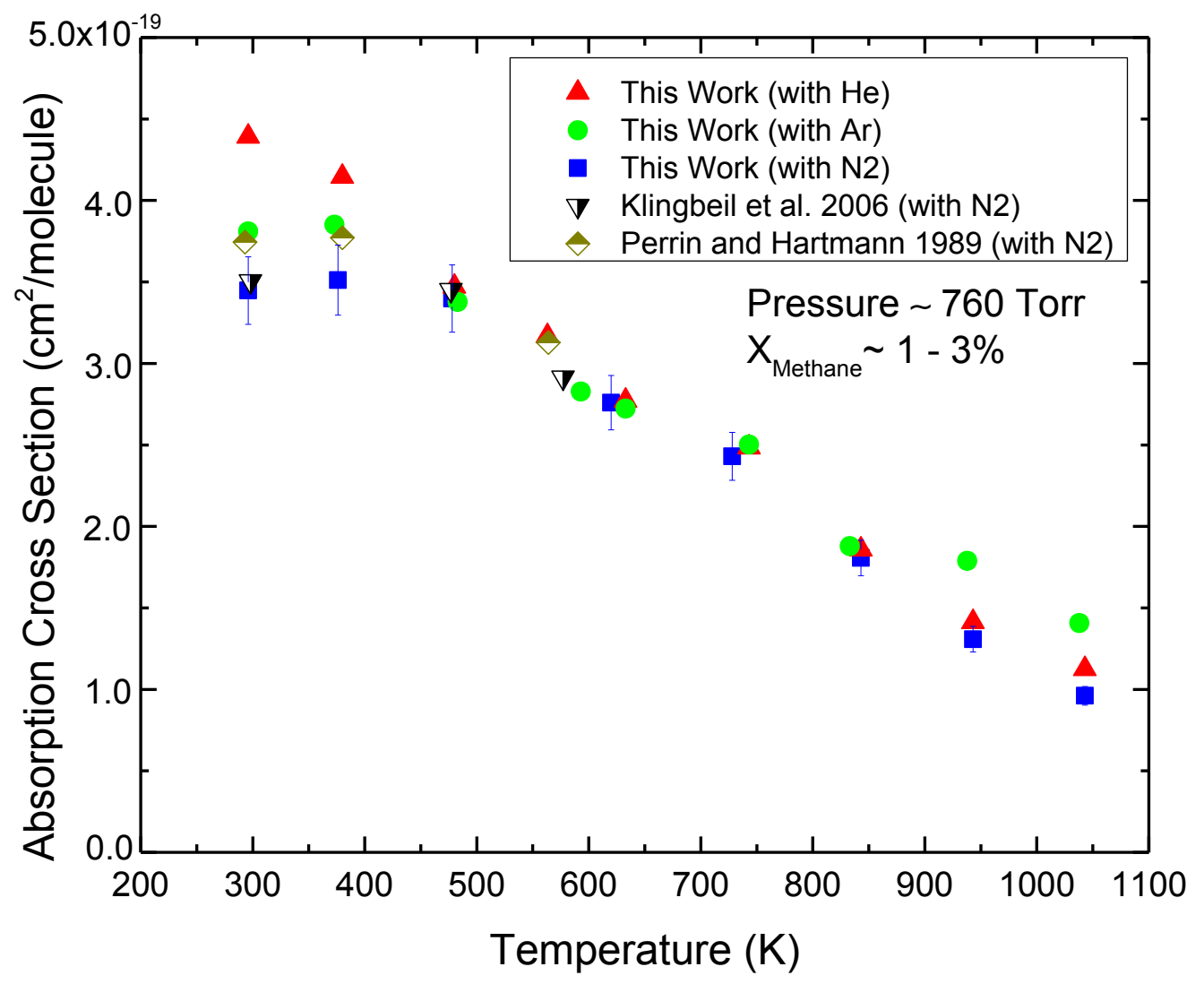


Figure 7. Bath gas dependent absorption cross-sections of methane with Ar, $\mathrm{He}$ and $\mathrm{N}_{2}$ at $296 \mathrm{~K}$. Measurements are carried out with HeNe laser at $3.392 \mu \mathrm{m}$.

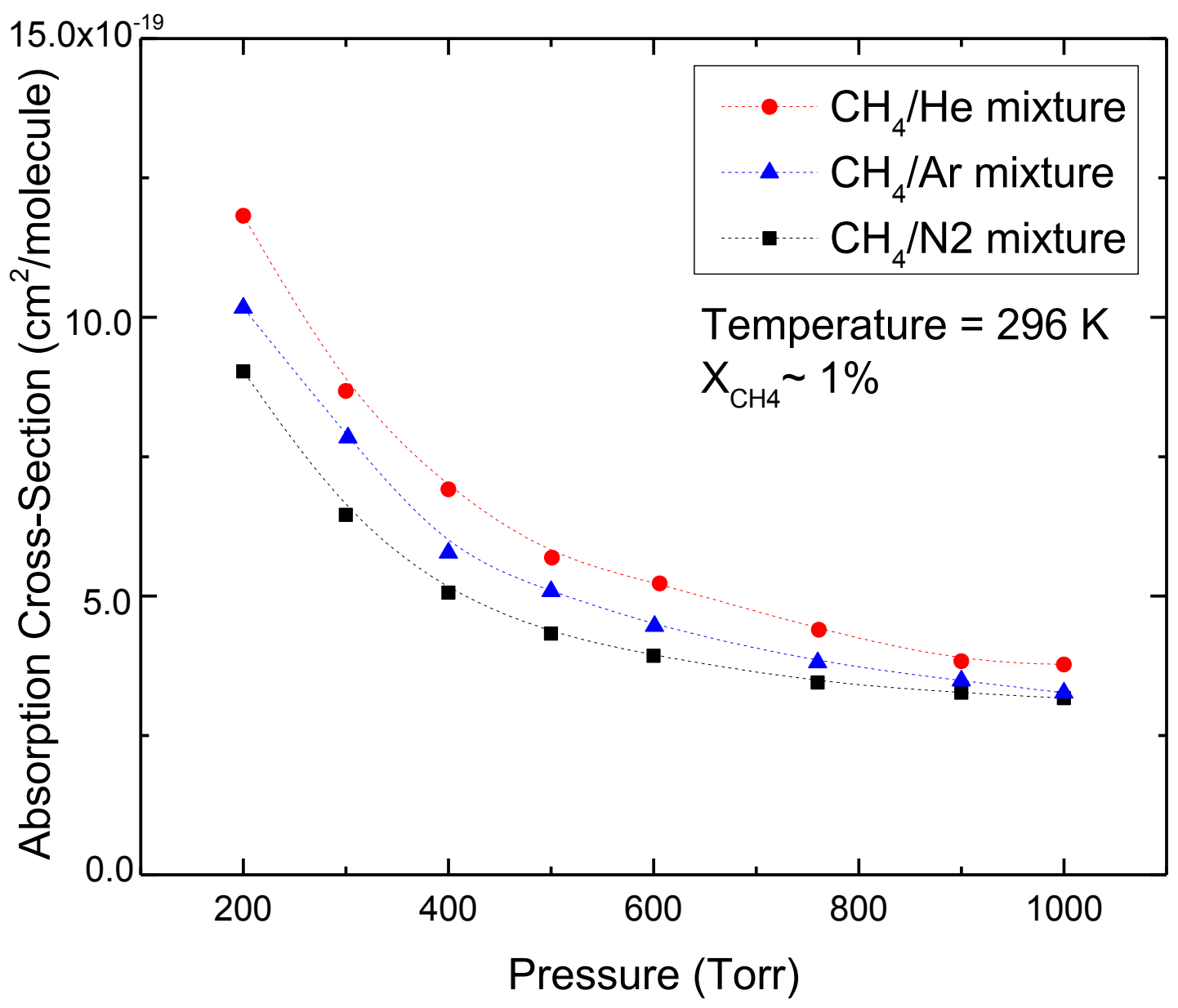


Figure 8. Absorption cross-sections of methanol, measured by HeNe laser (3392 nm), with different bath gases (Ar, He and $\mathrm{N}_{2}$ ).

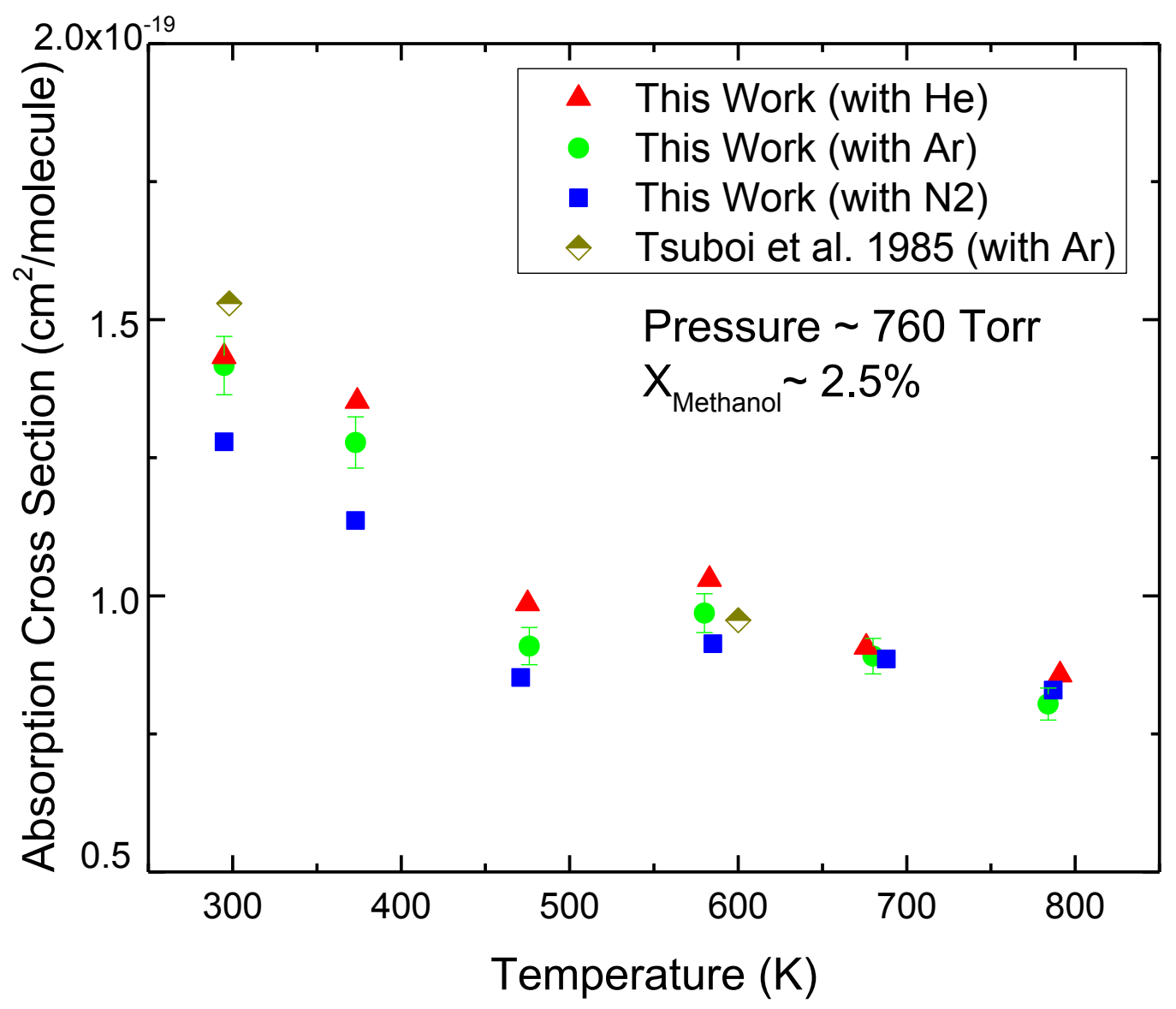


Figure 9. Absorption cross-sections of ethylene, measured by HeNe laser (3392 nm), as a function of temperature and bath gases $\left(\mathrm{He}, \mathrm{Ar}, \mathrm{N}_{2}\right)$.

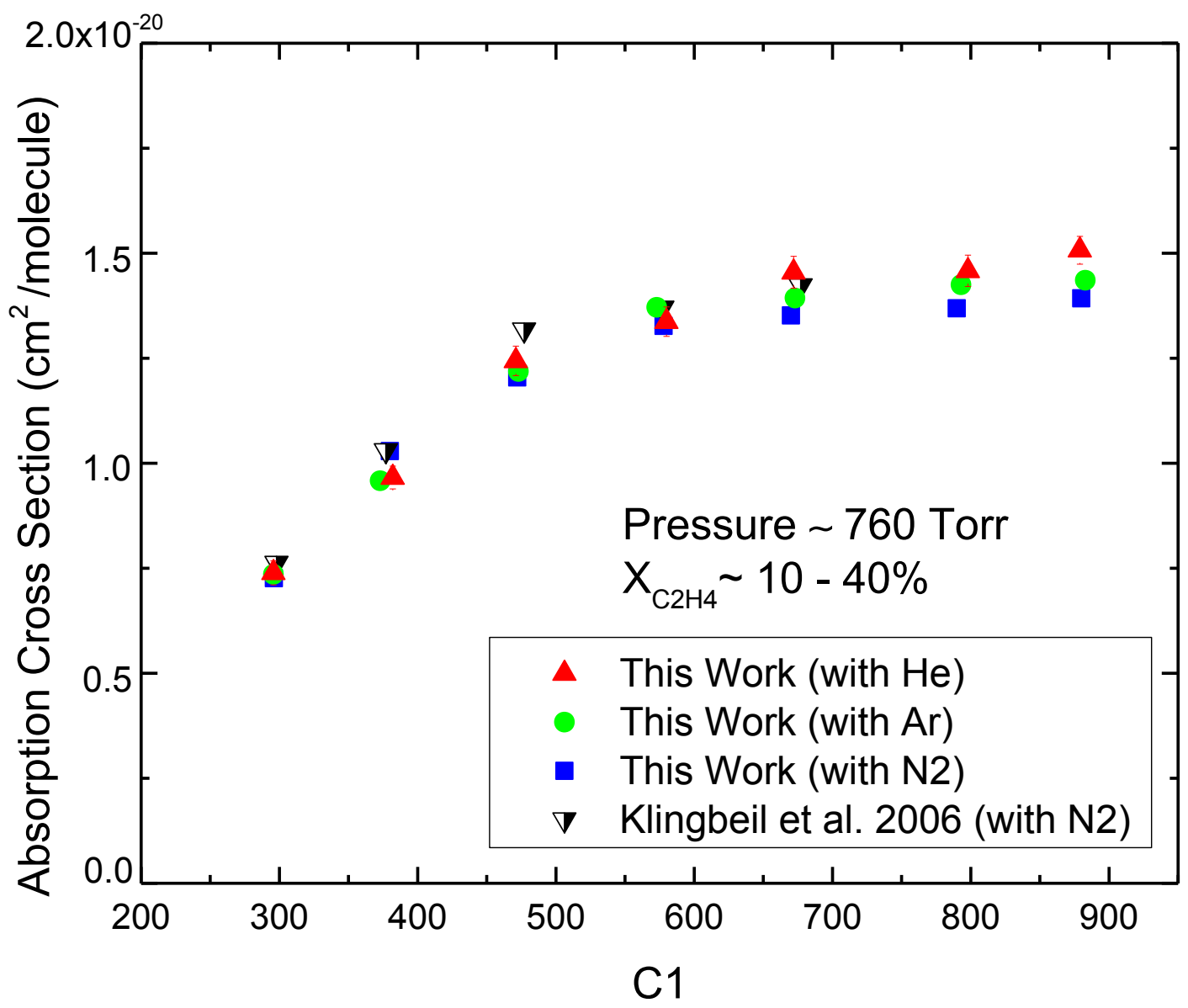


Figure 10. Absorption cross-sections of ethane, measured by HeNe laser (3392 nm), as a function of bath gases ( $\left.\mathrm{He}, \mathrm{Ar}, \mathrm{N}_{2}\right)$.

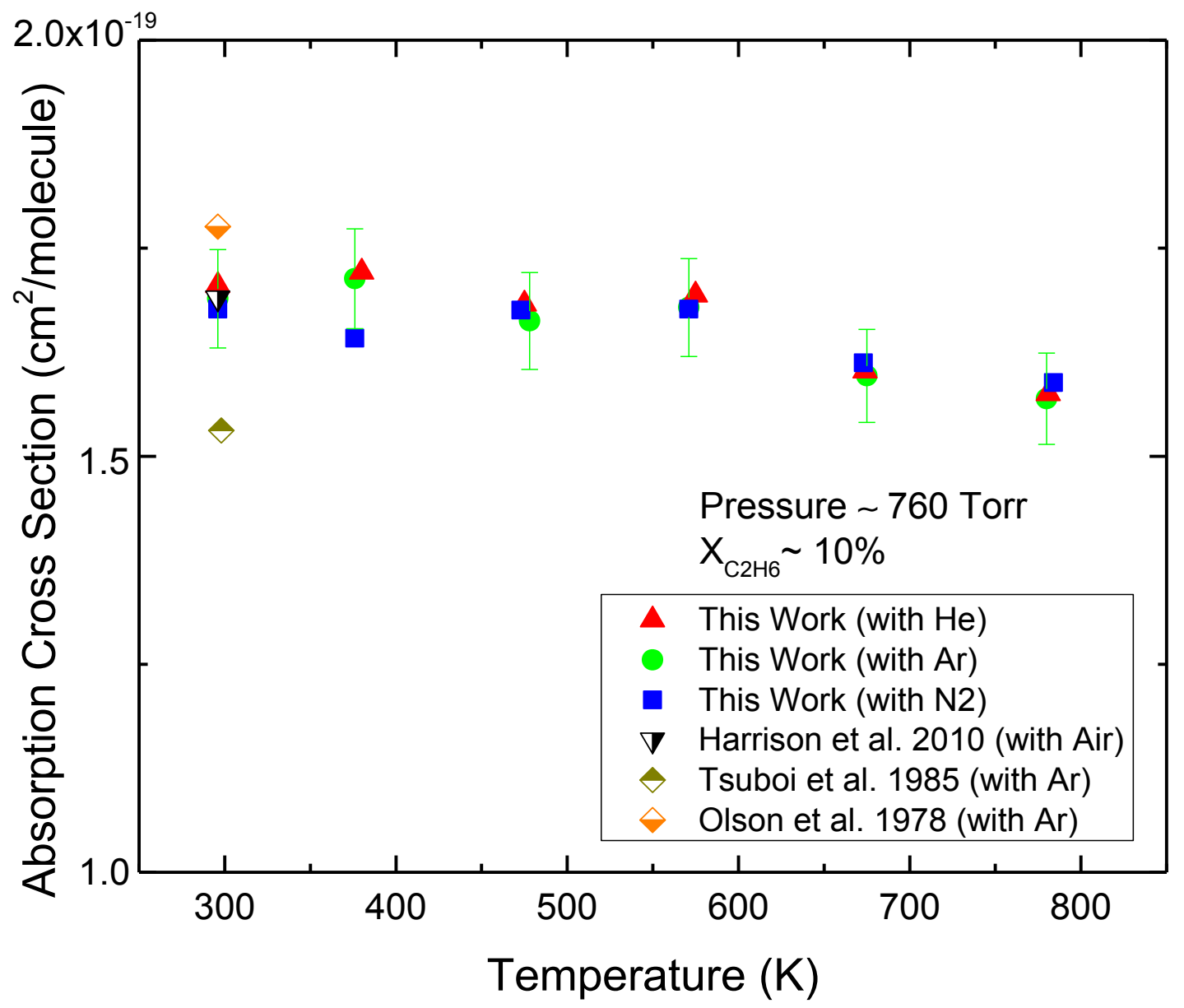




\section{References}

[1] D. Richter and P. Weibring, "Ultra-high precision mid-IR spectrometer I: Design and analysis of an optical fiber pumped difference-frequency generation source," Applied Physics B: Lasers and Optics, vol. 82, pp. 479-486, // 2006.

[2] W. Chen, J. Cousin, E. Poullet, J. Burie, D. Boucher, X. Gao, et al., "Continuous-wave mid-infrared laser sources based on difference frequency generation," Comptes Rendus Physique, vol. 8, pp. 1129-1150, // 2007.

[3] M. E. MacDonald, W. Ren, Y. Zhu, D. F. Davidson, and R. K. Hanson, "Fuel and Ethylene Measurements during $\mathrm{n}$-dodecane, methylcyclohexane, and iso-cetane pyrolysis in shock tubes," Fuel, 2012.

[4] A. E. Klingbeil, J. B. Jeffries, and R. K. Hanson, "Temperature-dependent mid-IR absorption spectra of gaseous hydrocarbons," Journal of Quantitative Spectroscopy and Radiative Transfer, vol. 107, pp. 407-420, // 2007.

[5] E.-t. Es-sebbar, Y. Benilan, and A. Farooq, "Temperature-dependent absorption cross-section measurements of 1-butene (1-C4H8) in VUV and IR," Journal of Quantitative Spectroscopy and Radiative Transfer, vol. 115, pp. 1-12, 1// 2013.

[6] E. T. Es-sebbar, M. Alrefae, and A. Farooq, "Infrared cross-sections and integrated band intensities of propylene: Temperature-dependent studies," Journal of Quantitative Spectroscopy and Radiative Transfer, vol. 133, pp. 559-569, // 2014.

[7] T. Etzkorn, B. Klotz, S. Sørensen, I. V. Patroescu, I. Barnes, K. H. Becker, et al., "Gas-phase absorption cross sections of 24 monocyclic aromatic hydrocarbons in the UV and IR spectral ranges," Atmospheric Environment, vol. 33, pp. 525-540, 2// 1999.

[8] J. J. Harrison, N. D. C. Allen, and P. F. Bernath, "Infrared absorption cross sections for ethane $(\mathrm{C} 2 \mathrm{H} 6)$ in the 3\&\#xa0; $\mu \mathrm{m}$ region," Journal of Quantitative Spectroscopy and Radiative Transfer, vol. 111, pp. 357-363, 2// 2010.

[9] J. J. Harrison, N. D. C. Allen, and P. F. Bernath, "Infrared absorption cross sections for methanol," Journal of Quantitative Spectroscopy and Radiative Transfer, vol. 113, pp. 2189-2196, // 2012.

[10] J. J. Harrison and P. F. Bernath, "Infrared absorption cross sections for propane (C3H8) in the 3\&\#xa0; $\mu \mathrm{m}$ region," Journal of Quantitative Spectroscopy and Radiative Transfer, vol. 111, pp. 1282-1288, 6// 2010.

[11] L. S. Rothman, I. E. Gordon, Y. Babikov, A. Barbe, D. Chris Benner, P. F. Bernath, et al., "The HITRAN2012 molecular spectroscopic database," Journal of Quantitative Spectroscopy and Radiative Transfer, vol. 130, pp. 4-50, 11// 2013.

[12] P. M. Chu, F. R. Guenther, G. C. Rhoderick, and W. J. Lafferty, "The NIST quantitative infrared database," Journal of Research of the National Institute of Standards and Technology, vol. 104, pp. 59-81, // 1999.

[13] S. W. Sharpe, T. J. Johnson, R. L. Sams, P. M. Chu, G. C. Rhoderick, and P. A. Johnson, "Gas-phase databases for quantitative infrared spectroscopy," Applied Spectroscopy, vol. 58, pp. 1452-1461, // 2004.

[14] D. B. Olson, W. G. Mallard, and W. C. Gardiner Jr, "HIGH TEMPERATURE ABSORPTION OF THE 3. 39 mu m He-Ne LASER LINE BY SMALL HYDROCARBONS," Applied Spectroscopy, vol. 32, pp. 489493, // 1978.

[15] W. G. Mallard and W. C. Gardiner Jr, "Absorption of the $3.39 \mu \mathrm{m}$ He-Ne laser line by methane from 300 to $2400 \mathrm{~K}$," Journal of Quantitative Spectroscopy and Radiative Transfer, vol. 20, pp. 135-149, 8// 1978. 
[16] K. I. Takao Tsuboi, Yutaka Tsunoda, Akihito Isobe and Koh-ichi Nagaya "Light absorption by hydrocarbon molecules at $3.392 \mu \mathrm{m}$ of He-Ne laser," Japan. J. Appl. Phys., vol. 24, pp. 8-13, 1985.

[17] M. Y. Perrin and J. M. Hartmann, "High temperature absorption of the $3.39 \mu \mathrm{m}$ He-Ne Laser line by Methane," Journal of Quantitative Spectroscopy and Radiative Transfer, vol. 42, pp. 459-464, $12 / / 1989$.

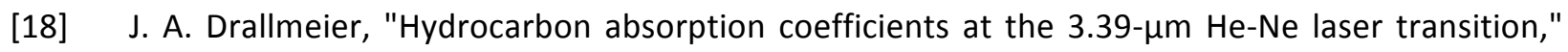
Applied Optics, vol. 42, pp. 979-982, // 2003.

[19] A. E. Klingbeil, J. B. Jeffries, and R. K. Hanson, "Temperature- and pressure-dependent absorption cross sections of gaseous hydrocarbons at $3.39 \mu \mathrm{m}, "$ Measurement Science and Technology, vol. 17, p. 1950, 2006.

[20] R. Mével, P. A. Boettcher, and J. E. Shepherd, "Absorption cross section at 3.39\&\#xa0; $\mu \mathrm{m}$ of alkanes, aromatics and substituted hydrocarbons," Chemical Physics Letters, vol. 531, pp. 22-27, 4/2/ 2012.

[21] N. M. Marinov, W. J. Pitz, C. K. Westbrook, A. M. Vincitore, M. J. Castaldi, S. M. Senkan, et al., "Aromatic and polycyclic aromatic hydrocarbon formation in a laminar premixed n-butane flame," Combustion and Flame, vol. 114, pp. 192-213, // 1998.

[22] G. Herzberg, Molecular Spectra And Molecular Structure: Infrared and Raman Spectra of Polyatomic Molecules vol. II. Malabar, Florida 32950: Krieger Publishing Company, 1991.

[23] A. E. Klingbeil, "MID-IR laser absorption diagnostics for hydrocarbon vapor sensing in harsh environments," PhD, Mechanical Engineering, Stanford University, 2007.

[24] S. D. Williams, T. J. Johnson, S. W. Sharpe, V. Yavelak, R. P. Oates, and C. S. Brauer, "Quantitative vapor-phase IR intensities and DFT computations to predict absolute IR spectra based on molecular structure: I. Alkanes," Journal of Quantitative Spectroscopy and Radiative Transfer, vol. 129, pp. 298-307, 11// 2013.

[25] J. C. Breeze, C. C. Ferriso, C. B. Ludwig, and W. Malkmus, "Temperature Dependence of the Total Integrated Intensity of Vibrational-Rotational Band Systems," The Journal of Chemical Physics, vol. 42, pp. 402-406, 1965.

[26] S. J. Yao and J. Overend, "Vibrational intensities-XXIII. The effect of anharmonicity on the temperature dependence of integrated band intensities," Spectrochimica Acta Part A: Molecular Spectroscopy, vol. 32, pp. 1059-1065, // 1976.

[27] A. S. Pine, "N2 and Ar broadening and line mixing in the $P$ and R branches of the $v 3$ band of CH4," Journal of Quantitative Spectroscopy and Radiative Transfer, vol. 57, pp. 157-176, // 1997.

[28] N. A. Takao Tsuboi, Du Ping, Jean-Michel Hartmann, "Temperature, Density, and Perturber Dependences of Absorption of the 3.39 \$mu\$m He\&\#8211;Ne Laser by Methane," Japanese Journal of Applied Physics, vol. 29, 1990. 